\title{
As cotas raciais na construção da democracia
}

\section{Eliaidina Wagna Oliveira da Silva ${ }^{1}$}

\section{Alba Janes Lima²}

\section{Racial quotas in the construction of democracy}

da Santa Casa de Misericórdia. Contato: adnasilva@msn.com.

${ }^{2}$ Doutoranda em Música pelo IFES. Contato: albajanes@hotmail.com. 


\title{
Resumo
}

Esse estudo expõe aos movimentos representativos atuantes contra as disparidades sociorraciais e educacionais, uma leitura das ações afirmativas como remédio de garantia da igualdade material. Aponta o caminhar do Estado Democrático de Direito rumo a uma nação participativa e multicultural, militando inclusões sociais positivas em cujo manifesto pelas diversidades rompem invisibilidades das minorias negras ao compartilhar espaços acadêmicos por meio das cotas raciais. Trata-se de artigo bibliográfico com análise descritiva respaldada na Constituição Federal e produções de Fernandes (2008a, 2008b, 2013, 2017) dialogadas com estudiosos da causa negra, para compreensão do impacto do racismo sobre os corpos negros e das proteções constitucionais contra grupos reacionários.

Palavras-chave: Democracia; Cotas; Educação; Racismo.

\begin{abstract}
The study exposes to the representative movements acting against socio-racial and educational disparities, a review of affirmative actions as a remedy to guarantee material equality. It points out the path of the Democratic Rule of Law (Rechtsstaat), towards a participatory and multicultural nation, implying positive social inclusions, in whose manifesto for the diversity they break invisibilities of the black minorities when sharing academic spaces through racial quotas. This is a bibliographic article with descriptive analysis supported by the Federal Constitution and productions by Fernandes (2008a, 2008b, 2013, 2017) dialogued with scholars of the black cause, to understand the impact of racism on black bodies and constitutional protections against reactionary groups.
\end{abstract}

Keywords: Democracy; Quotas; Education; Racism. 


\section{Introdução}

As cotas raciais que reservam vagas para negros nas universidades públicas é uma inovação normativa da Lei $n^{\circ} 12.711$, de 29 de agosto de 2012 (BRASIL, 2012). Trata-se de ações afirmativas que propiciam a inclusão do negro no ensino superior em um espaço que era restrito a um grupo dominante. Isso democratiza o sistema educacional que sempre foi disponibilizado à população branca detentora do poder político e das balizas econômicas. Desse modo, as vagas das universidades públicas expandem-se aos segregados raciais em uma igualdade de oportunidades, consoante os preceitos democráticos.

Essas políticas constituem uma adequação das oportunidades para negros e brancos, com critérios menos desiguais. Contudo, a insatisfação de uma parte da elite dominante levanta-se contra essas ações afirmativas ao argumento de que as cotas representam o antítese da igualdade de todos perante a lei. Alegam ainda, que as questões sociais no Brasil são hierarquizadas por disparidades de exclusivo caráter econômico porque não existe obstáculos de cunho racial em terras brasileiras, para se justificar reservas de vagas para negros.

Essa propagada liderança dos mais meritórios encontra rebanho para uma defesa no mito da democracia racial, cujo discurso de harmonia na convivência das raças, nada mais é do que um raciocínio hediondo capaz de militar as injustiças sociais por não se sustentar em igualdade distributiva.

Necessita-se que políticas públicas propiciem a reparação dos efeitos da segregação racial a que foi submetida a população negra. A efetivação da norma impõem o manejo das ferramentas jurídicas à proteção de medidas com potencialidade para atenuar desigualdades sociais ameaçadas pelo ímpeto de autopreservação dos privilégios de segmentos dominantes.

Esse artigo evidencia que as cotas são uma conquista da comunidade negra. Trata-se de política que opera na construção de uma democracia com o anseio por uma sociedade igualitária por meio de acesso à educação a todos os cidadãos. As defesas dessas conquistas têm que ser contínua, diante de insatisfação daqueles que conspiram contra os avanços sociais, munidos do discurso de inexistência de segregação racial. 
A pesquisa é bibliográfica, de cunho qualitativo, caracterizando-se, segundo seu objetivo, como descritiva. Fez-se uma análise das ações afirmativas sob a ótica do instituto democrático positivado pela Epístola Constitucional (BRASIL, 1988), reduto de proteção das garantias sociais de inclusão social positiva.

As políticas de inclusão racial encontram abrigo constitucional, nesse estudo, na compreensão dos textos de Almeida (2018), Amaro (2015), Nascimento (2016) e outros pesquisadores comprometidos com o diagnóstico do impacto do racismo sobre os corpos negros, interpretados em consonância com as obras de Fernandes (2008a, 2008b, 2013, 2017).

Conclui-se que mais do que acesso à mobilidade social nas ascensões socioeconômicas a um grupo exposto ao atraso em decorrência da escravização, as cotas raciais propiciam um maior convívio dos negros e brancos dentro dos espaços universitários. Essa proximidade abre brechas para visões multiculturalistas que contribui na desestruturação dos preconceitos, por meio do reconhecimento de valores e diversidades.

\section{Desenvolvimento}

Embora insistam que no Brasil não há barreiras raciais, mas socioeconômicas (como se o racismo não fosse também um problema social), as estatísticas não escondem o apartheid existente nas disparidades culturais de negros e brancos. A segregação não se diluiu com o mero decorrer dos anos, uma vez que a abolição do negro é uma construção que se perpetua como uma característica intrínseca à estrutura da sociedade.

Passados 132 anos da Abolição da Escravatura, Lei Áurea de 1888, nenhuma política de inclusão social positiva foi impactada aos negros até o Estatuto da Igualdade Racial (BRASIL, 2010) seguidas das cotas raciais. Manteve-se uma ideia de que o simples passar dos anos, por si, encarregaria de incorporá-los no sistema da concorrência.

Porém, marginalizados, os negros não foram beneficiados no pós-abolição, com políticas de integração ao processo competitivo do mercado de trabalho e sofreram impactos negativos com a alteração nas relações de produção (FERNANDES, 2008a). 
Fernandes (2008a, 2008b, 2013) denunciou que o negro foi desagregado do sistema escravocrata sem ser preparado para o trabalho livre e a Colônia elegeu a mão de obra europeia acostumada com as implicações econômicas e sociais do novo regime de produção. Segundo o autor, a posição do liberto na ordem econômica passou de longe das preocupações por uma política específica.

Confere-se que os reflexos negativos desses fatores históricos-sociais reproduzem-se nas mais variadas estatísticas que confirmam a posição desprestigiada do negro, que não é apenas no campo socioeconômico, mas em todos as esferas da sua vida social. A população negra foi condenada ao isolamento nos setores residuais, sem agregação no mercado competitivo.

Consoante Fernandes (2013), a demagogia de que se dando tempo ao tempo, sem mecanismos de inclusão, colidiu com a condição social dos povos negros emperrada na indiferença política quanto aos seus destinos. Esse período de transição indefinida desde a abolição careceu de uma intervenção estatal e o Brasil ficou sob o jugo de nunca se espelhar em uma estruturação democrática em sua essência.

O racismo existe. Embora negado, os resultados de sua prática não se podem esconder porque se revela nas constatações das desigualdades de suas raças em todos os estratos socioeconômicos. Desse modo, as ações afirmativas vai além da reparação histórica para representar a interação das raças fora daquela naturalizada retratação dos negros em inferioridade hierárquica.

\section{O mito da democracia racial como ferramenta de dominação}

Uma sociedade não pode ser considerada inclusiva e participativa apenas porque ausente relações de conflitos raciais abertos nas suas comunidades. A ausência de rixas no Brasil é muito mais os efeitos sociopáticos da desorganização social permanente e da integração deficiente que se perdurou. Essa anomia provocou a total apatia do negro pelo seu destino, tornando-se um não-concorrente dos espaços de poder com o branco durante muito tempo (FERNANDES, 2008a, 2013).

Óbvio que a história registra passagens como a de Manoel da Motta Monteira Lopes, o primeiro deputado federal negro eleito apenas 11 anos após a 
abolição, que fez carreira como juiz, promotor e advogado. Com atuação destacada em prol dos operários e conhecido como defensor dos negros, o jurista representou exceções dentro de um contingente populacional negro (DANTAS, 2008).

Conforme Fernandes (2008a), à medida em que o negro não disputou com o branco as mesmas oportunidades por privação de recursos e ficou apático das conquistas por espaço, não houve hostilidade manifesta nos relacionamentos raciais. A ausência de agressividade acobertou a isenção de responsabilidade e até mesmo de solidariedade do branco com o destino do negro.

Para Fernandes (2008a), os libertos não foram descravizados porque com o abolicionismo não veio de políticas de inclusão social positiva. A substituição por imigrantes europeus foi uma tentativa de embranquecimento da população. Nessa dinâmica, segundo o autor, no processo pós-abolição, os negros sequer representaram ameaça na competitividade dentro do mercado de trabalho.

Não obstante, alguns historiadores registram vestígios do labor de comunidades negras nas fábricas como operários e abrindo estradas em meio a imigrantes europeus e nacionais brancos. Também foi investigada a presença negra no carregamento de sacas de café nos portos e outras atividades. Até mesmo na atuação sindical mobilizando greves, instituindo movimentos coletivos pode-se conferir o desempenho dos libertos (ANDREWS, 1998; CRUZ, 2005; SOUZA, 2010).

Fernandes (2008a, 2008b) argumenta contudo que se houve nivelamento de negros e brancos no mercado de trabalho, esse equiparação se deu por meio de uma nivelação feita por baixo. Ao ver do autor, as exterioridades ajustamentos raciais forjaram uma falsa consciência da realidade. Essa alienação calcificou uma postura rácica no seio de uma sociedade deficiente de democracia na medida em que os grupos raciais foram hierarquizados na pirâmide socioeconômica, conforme a cor da pele e traços fenótipos.

Para o sociólogo, essa limitação da competitividade resultou, no início da industrialização, na exclusão do negro na mobilidade social vertical por ausência de condição de se aparelhar na ordem capitalista, em termos de competitividade. Notase que a ocupação da base da pirâmide socioeconômica pela população negra faz a assertiva de Fernandes (2008a e 2008b) factual. 
Destarte, o discurso da dissimulada democracia racial presas às questões econômicas não passa de uma justificativa descabida para a segregação racial, com a negativa de que a repressão discriminatória não propiciou uma agenda política de inclusão social positiva.

Como inferência, a chamada democracia racial é a naturalização do racismo manipulado por subterfúgios com o pretexto de se maquiar a segregação como uma causa apenas econômica. Porém, não passa de uma estratégia de dominação que antes era mantida pela força do braço estatal e na atualidade opera-se por meio de uma "estratificação racial disfarçada" (AMARO, 2015, n.p.).

Por conta disso, Nascimento (2016) denuncia a falácia na harmonia racial em que os negros não dispõem das mesmas oportunidades nem desfrutam dos mesmos espaços. Para o autor, as relações de raça no Brasil escoram-se em uma ficção de democratismo racial e acoberta um perigoso e extremo racismo porque seu efeito prático não é promover o igualitarismo.

O ativista acusa o mito da democracia racial a servir a um ideal de branqueamento que naturaliza o monopólio do poder branco, onde a mera presença de uma pessoa de cor negra no espaço público representa ameaça (NASCIMENTO; 2016). Nessa compreensão, Fernandes (2008) insere que se trata de uma manipulação "[...] dinâmica dos mecanismos societários de defesa dissimulada de atitudes, comportamentos e ideais 'aristocráticos' da 'raça dominante' [...]" (FERNANDES, 2008).

Ao ver de Nascimento (2016), a dissimulação de harmonia racial no Brasil diferencia-se das relações americanas com conflitos aparentes. $O$ mito da democracia racial é "[...] a metáfora perfeita para designar o racismo estilo brasileiro [...]" (NASCIMENTO, 2016, n.p.), no qual se mantém intocada a crença na inferioridade africana, com restrição na mobilidade vertical. Denuncia ele:

O preconceito de cor, a discriminação racial e a ideologia racista permaneceram disfarçados sob a máscara da chamada "democracia racial", ideologia com três principais objetivos: 1. impedir qualquer reivindicação baseada na origem racial daqueles que são discriminados por descenderem do negro africano; 2. assegurar que todo o resto do mundo jamais tome consciência do verdadeiro genocídio que se perpetra contra o povo negro do país; 3. aliviar a consciência de culpa da própria sociedade brasileira que agora, mais do que nunca, está exposta à crítica das nações africanas independentes e soberanas, das quais o Brasil oficial 
pretende auferir vantagens econômicas. (NASCIMENTO, 2016, n.p.).

Percebe-se que cotas criadas para favorecimento de grupos específicos não é novidade no Brasil. No passado, o governo brasileiro instituiu leis de cotas para o ensino público no campo rural aos que atuassem no âmbito agrícola, fossem ou não, proprietários de terras (BRASIL, 1968). Todavia, a pouca divulgação favoreceu os filhos de fazendeiros, compostos pela maioria branca.

Diante disso, Silva (2020) denuncia que a Lei n. ${ }^{\circ} 5.456$, de 3 de julho de 1968 (BRASIL, 1968) que ficou estigmatizada como a "Lei do Boi", reservou 50\% de suas vagas a agricultores e seus filhos. Vigorou até 1985, logo, por 17 anos beneficiando, em larga escala, aos fazendeiros e descendentes. Muitos agrônomos e veterinários, que tiveram acesso ao ensino público gratuito, usufruíram das vagas sem que as cotas fossem objeto de controvérsias e altercações das mídias.

Também existem cotas para deficientes (BRASIL, 1991). No campo eleitoral há cotas para mulheres no registro de disputas eletivas (BRASIL, 1995). Também há reservas de vagas no ensino público para estudantes de baixa renda e oriundos das escolas públicas (BRASIL, 2012). Registra-se, contudo, o histórico de políticas públicas voltadas, em sua maior parte, aos interesses do grupo detentor do capital socioeconômico e político.

Curioso que nenhum tipo de reserva social direcionada ao favorecimento de grupos específicos sofreu, e persiste com mais polêmica em torno de discursões, cercada de aversões e reações contrárias, do que as Leis de Cotas Raciais nas Universidades e Concursos Públicos (BRASIL, 2012, 2014). Fica evidente que são elas, as reservas de vagas para negros, o que representa ameaça á supremacia elitista branca.

Por isso, pretextos como inexistência de raças, meritocracia, estímulos a atritos raciais decorrentes de uma suposta separação das raças estimulada pelo governo, não passam de uma grande falácia. Verdade que sob uma ótica científica a raça humana seja única, mas essa formulação com viés histórico segregacionista serviu como meio de subjugação dos povos negros e conceito social de raça ainda designa segregação.

Ademais, essa resistência de enfrentamento do tema por brasileiros que insistem com o mito da democracia racial, já é um meio pelo qual o racista se constrange em não se manifestar mas vai se petrificando em uma prática rácica, 
oculta e perversa. Trata-se de uma realidade cruel, porque dissimulada sob um manto de harmonia das raças que, na prática, encobre a desigualdade de competição e perpetua os privilégios de uma elite branca, em uma nítida definição de espaços onde o lugar do negro é na base da pirâmide socioeconômica.

$\mathrm{Na}$ verdade, o mito da democracia racial é uma tecnologia do poder dominante para ocultar a perversidade da estratificação racial de desigualdade extrema que acaba por se revelar no racismo. Com essa compreensão, Fernandes denuncia que "[...] mitos existem para esconder a realidade. Por isso mesmo, eles revelam a realidade íntima de uma sociedade [...]". (FERNANDES, 2017, p. 31).

Como dito, um dos maiores obstáculos na democratização de acesso equânime dos direitos das raças é o discurso do dominador em torno da democracia racial. Esse mito tomou dimensão tamanha na sociedade, a ponto de o Conselho Federal da Ordem dos Advogados do Brasil ingressar com a ADIN n. 41 - Ação Declaratória de Constitucionalidade (BRASIL, 2017) da Lei de Cotas em Concursos Públicos (BRASIL, 2014).

Pretendeu-se com a declaração de constitucionalidade (BRASIL, 2017) da Lei n. ${ }^{\circ}$ 12.990, de 9 de junho de 2014 (BRASIL, 2014) pacificar controvérsias e repelir demandas difusas, provenientes do descontentamento de alguns detentores do poder econômico insatisfeitos com o partilhar dos privilégios.

A Suprema Corte julgou pela constitucionalidades das Leis de Cotas nas universidades e nos concursos públicos, após considerar a proteção aos núcleos de garantias individuais mais relevantes como a igualdade de todos independente de cor, credo ou sexo, na efetivação da democracia. Essa é a missão precípua do Regime Republicano e Democrático que tem por sua natureza, ser um Estado inclusivo.

Na ocasião, o Ministro Celso de Mello (2017) asseverou que o pender da balança patenteada pela política das cotas raciais harmoniza-se com a ideia de equidade. Essa posição foi motivada pela necessidade de ultrapassar o racismo estrutural ainda existente na sociedade brasileira.

Nesse contexto, governo e sociedade não podem permanecer de braços inertes frente a perseverança das mazelas sociais produzidas pela segregação racial camuflada de inexistente. Precisa-se antes, garantir meios de alcançar a igualdade material dos cidadãos. 


\section{As Ações Afirmativas como ferramenta da democracia}

Desde os gregos da Era Aristotélica e perpassando pela Declaração Francesa, o que dita a máxima da igualdade e da dignidade humana é a aferição da democracia. Trata-se da tríade francesa: Liberdade, Igualdade e Fraternidade.

Barbosa (1920), na famosa "Oração dos Moços", conceituou de forma didática o que não se pode definir como sendo igualdade: "[...] Tratar com desigualdade a iguais, ou a desiguais com igualdade, seria desigualdade flagrante, e não igualdade real“. Nessa linha, o Brasil dispõem de medidas concretas a reduzir as injustiças sociais pela promoção do bem de todos sem preconceito ou quaisquer outros aspectos de discriminação.

Dias (2017) lembra que a existência do Estado só se justifica no atendimento de necessidades sociais específicas com foco na diminuição das desigualdades. As ações afirmativas é ferramenta de efetividade dessa base igualitária cuja sustentação é a dignidade da pessoa, o requisito sem o qual uma nação não é democrática no plano internacional.

Todavia, apesar de representar a predominância numérica das gentes brasileiras, os negros são minorias (caracterizados não por uma circunstância inferior em termos numérico, mas por fatores de vulnerabilidades sociais, econômicas e políticas) porque apresentam os piores índices de escolaridade, moradia, segurança, remuneração e acesso aos serviços públicos de transporte.

No que se refere às minorias negras, essa colocação é singular. Trata-se de extratos marginalizados e condicionados, de modo desagregado, pela parte majoritária (inferior em números, mas detentora do capital político) com o estigma da marca e alta carga de vulnerabilidade socioeconômica a reclamar tratamento isonômico.

A ação afirmativa tem a finalidade de romper com a anomalia social do negro e se justifica nas agudas discrepâncias socioeconômicas e educacionais. As amostragens de pesquisas que atestam a efetivação destas políticas demonstram de que elas cumprem o papel de democratização do ensino universitário. A respeito, o Grupo de Estudos Multidisciplinares da Ação Afirmativa (GEMAA), destaca que: 
[...] houve um incremento significativo na presença de pretos e pardos nas universidades federais. Em 2003, os pretos representavam 5,9\% dos alunos, e pardos, 28,3\%. Já em 2014, essas proporções aumentaram para $9,8 \%$ e $37,8 \%$, respectivamente, de forma que, no agregado, passamos de $34,2 \%$ de pretos e pardos no total de alunos para 47,5\% (GEMAA, 2016, p. 3-4). A pesquisa comissionada pela Associação Nacional dos Dirigentes das Instituições Federais de Ensino Superior (Andifes) atribui esse aumento às políticas de ação afirmativa, que começaram a ser aplicadas nessas instituições gradualmente a partir de meados da década passada. A mesma pesquisa também aponta que a proporção de alunos das classes C, D e se elevou de 42,8\%, em 2003, para 51,5\%, em 2014 (RIO DE JANEIRO, 2018, p.3).

As ações afirmativas de cotas raciais foram o resultado da luta negra (GOMES, 2019, n.p.). A conquista certifica um paulatino ganho de espaço de poder e é fruto das reivindicações pela universalização de acesso aos direitos sociais. Destarte, se houver um corte nas reservas de vagas em tempo insuficiente, a ruptura implicaria no corte de uma política que vem surtindo efeito positivo na quebra das desigualdades.

Uma das peculiaridades do Estado Democrático de Direito, como é o caso da Nação Brasileira sob a égide da Constituição Cidadã de 1988, é a implementação dos direitos sociais focados no alcance da igualdade material e no combate a toda forma de preconceito. Essa é a base e o valor máximo da nossa Carta Política por força de seus princípios implícitos e explícitos que impulsiona a redução das desigualdades e anseia por uma sociedade inclusiva.

Sob essa ótica, Fernandes (2008) adverte que enquanto a sociedade relacionar a cor a uma posição social ínfima, a democracia continua impraticável até mesmo dentro de um padrão de economia capitalista. Para o autor, é evidente que mantida a plena ruína das minorias negra, a ordem social competitiva é desarticulada e não passa de uma mera falácia.

Carvalho (2002, p. 8-10) acusa que a grandes desigualdades sociais e econômicas do Brasil provocam enorme desgastes com potencialidade de causar o ceticismo da população nos agentes do sistema democrático. O autor enfatiza que as desagregações socioeconômicas são sobretudo racial e regional (produto de nosso histórico escravocrata) e que sua redução é uma invocação da justiça social que almeja a garantia de um mínimo de bem-estar social para todos. 
Desse modo, a dominação branca em todos os setores sociais resulta dos mais de três séculos de colonização que trouxe como reflexo, a paralisia da cidadania e, via de consequência, da democracia. Com essa conta, Carvalho (2003, p. 21) enuncia que a ausência da mínima noção de igualdade de todos retira não só do oprimido, mas também do opressor, a essência de condição de cidadão.

Assim, as disparidades socioeconômicas das raças não afeta apenas a população negra, mas a nação como um todo, no sentido de impedir a concretização de uma efetiva democracia com espírito de cidadania, para o qual é preciso que as desigualdades sejam menos acentuadas.

Diante da concepção de igualdade como modelo de um Estado Democrático, a normatividade dos princípios da democracia ${ }^{3}$ não se jubila com a sua mera formalidade. Estado e a sociedade devem assegurar a todos o direito de participar da vida política em condições paritárias, mas sem desconsiderar que a identidade democrática não é singular. Por isso, é importante que se imponha respeito pela diversidade e pelo pluralismo étnico-racial com suas multiplicidades de gêneros, valores, crenças e culturas.

Dentro do constitucionalismo democrático da nação brasileira, os influxos dos movimentos políticos devem atuar na garantia da cidadania plena e na defesa dos direitos das minorias por meio de mecanismos que garanta parcela do poder a todas as camadas sociais, sem discriminação.

Para Streck e Morais (2014), o Estado Democrático de Direito vincula seus princípios com uma constitucionalidade instrumentalizada no respeito à dignidade da pessoa, solidariedade e justiça social. Significa dizer que valores caros ao democratismo, como igualdade, liberdade e fraternidade sem mecanismos de proteção jurídica é uma insinceridade para com a cidadania participativa.

Streck e Morais (2014) aduzem a justiça social exige mecanismos políticos que corrijam as desigualdades. Para os autores, o Estado de Direito, ao assumir o feitio social, deve referendar a transformação do status quo. Destarte, que a lei deve ser uma ferramenta de transformação da sociedade.

Destarte, se o esqueleto da doutrina democrática sustenta-se na igualdade, todas as inovações normativas ou atuação governamental tem que desencadear

\footnotetext{
${ }^{3}$ A normatividade dos princípios constitucionais exige o efetivo e imediato cumprimento da Constituição.
} 
mecanismos de redução das desigualdades sociais, reprimindo marchas reacionárias carecedoras de lastro democrático.

Em consequência, um corte, ou mesmo uma redução prematura das cotas para negros nas universidades interdita o processo dos avanços sociais. Vai-se na contramão dos objetivos fundamentais da República Federativa do Brasil que dispõem, na Constituição Cidadã (BRASIL, 1988), a redução das desigualdades com democratização dos direitos por meio de inclusão positiva.

$\mathrm{Na}$ garantia das cotas raciais cita-se o princípio da proibição do retrocesso social. Por essa base, não é dado ao Poder Legislativo, na atuação legiferante, e muito menos ao Poder Executivo, na missão de cumpridor dos preceitos constitucionais, permissão para que reduza políticas públicas que dão eficácia a direitos sociais (LENZA, 2019).

Para Dotta e Marques (2017, p. 9) a exclusão de direitos sociais não é democrática porque "[...] ao dever positivo do Estado existe uma imposição de abstenção, ou seja, esse não poderia adotar medidas que flexibilizem as conquistas alcançadas na seara dos direitos sociais".

Destarte, o "Não Retrocesso4" é princípio que fornece aos direitos sociais uma segurança normativa fundada no princípio da confiança para estabilização de situações jurídicas como é o direito a igualdade (CARDOSO; CARDOSO; VAHL, 2015). Nessa lógica, as ações afirmativas por efetivar a redução das desigualdades, tem resguardo jurídico e não pode ser reduzido por mera prodigalidade sem correção das mazelas causadas pelo vergonhoso histórico escravocrata.

Ex-procuradora-geral da República, Raquel Dodge (2018) proferiu que a nação brasileira é para os brasileiros e o governo deve primar pelos interesses de todos: "A democracia orgulha todos os brasileiros, porque foi construída por todos. A democracia é o governo da maioria e o respeito à minoria" (DODGE, 2018, n.p.).

Por isso, a normatização que pretenda reduzir ou retirar as cotas para negros é eivada de ilegitimidade porque contraria a finalidade substancial da democracia que é a busca da redução das desigualdades sociais, o combate aos preconceitos e a garantia da representatividade de todos.

Em vista disso, tentativas de qualquer diminuição das cotas raciais é o inequívoco reflexo de um racismo brasileiro teimado em se camuflar no manto de

\footnotetext{
${ }^{4}$ O Princípio de Proibição do Retrocesso Social ou Princípio do Não Retrocesso Social.
} 
inexistência de intolerância racial, mas social. Essa ideia induz que negros são os mais desvalidos, porque não são esforçados o bastante ou suficientes meritosos.

Trata-se de um racismo à brasileira que Amaro (2015) chama de "estratégia de dominação secular reinventada" (AMARO, 2015, n.p.), onde a ausência de hostilidade é vista como ausência de racismo. Ocorre uma naturalização do segregacionismo sob a ideia de que os negros são pobres porque são acomodados. Esse senso comum objetiva constranger grupos oprimidos a se sentirem envergonhados pela própria discriminação.

Resultado disso, a afirmação de que o que se chamam de "meritocracia", finca suas bases na qualidade da educação recebida por valores alheios ao potencial cognitivo. Esses discursos de mérito e democracia racial acobertam uma segregação que tem de ser combatida pelos agentes políticos.

Nesse alerta, a proteção das conquistas das minorias face às eventuais maiorias tirânicas, que comandam o capital social e político, é têmpera comum a todas as democracias consolidadas. A Constituição do Brasil é sonora na preservação o regime democrático de direito e se opõem contra os movimentos especulativos e oportunistas.

Por consequência, princípios explícitos e implícitos convergem-se em impedir medidas restritivas aos direitos fundamentais do indivíduo como cidadão, por meio de inovações normativas.

Tem-se que a ordem democrática, já manifesta no Preâmbulo ${ }^{5}$ da Constituição Cidadã, é o vetor de interpretação dos seus valores com todo o arcabouço de artefatos para que os movimentos de luta reivindiquem dos agentes políticos de todas as esferas do poder, a defesa das prestações positivas pelo Estado quando voltadas na efetivação do direitos fundamentais e sociais.

Silva Filho (2016) faz um leitura de Bobbio referindo a democracia como um estado natural de construção e transformação de uma sociedade por um grupo coletivo que luta pelo apaziguamento das angústias sociais com integração das minorias por não aceitar as desigualdades como uma justificativa peculiar das diferenças.

${ }^{5}$ O Preâmbulo Constitucional traça diretrizes de cunho político, filosófico e ideológico. 
Fernandes (2013) salienta que o dilema racial no Brasil possui caráter estruturado. O seu enfrentamento só é possível com a correção dos arrimos de distribuição de rendas, de prestígio social e de poder. Sem equidade socioeconômica das raças não existe uma democratização.

Invocando a importância dos movimentos de luta, Fernandes (2008) enfatiza que "o dilema da democracia nesse país confunde-se com o dilema da condição do negro" (FERNANDES, 2008, n.p.). De modo que, não se pode dizer que uma sociedade é democrática com tantas disparidades socioeconômicas tão acentuadas porque sua essência não se ambienta na desigualdade.

\section{A convivência das diversidades como mecanismo de diminuição do preconceito}

Carvalho (2006) chama atenção ao fato de que a falta de acesso dos espaços educacionais pela população negra cria, por consequência, um isolamento mútuo que impacta nas relações raciais. A implementação das cotas nas universidades rompe com esta lógica de funcionamento acadêmico que distanciou, tanto o universo discente quanto o corpo docente da graduação, da convivência com outras culturas.

O autor chama a atenção para um caso específico que bem pode representar a realidade brasileira quando constatou que a Universidade de Brasília - UnB, inaugurada em 1961 com 200 professores, na época da pesquisa, contava 4 décadas de existência e possuía apenas 15 professores negros.

O paradoxal, revela o docente, é que as universidades públicas são concebidas como um ambiente em que se objetiva a inovação e a integração de uma sociedade consigo mesma e com o mundo. Todavia, durante décadas, nesse universo de inclusão formou-se um verdadeiro apartheid com exclusão racial extrema até no meio dos docentes. A exemplo, a curiosa narrativa apresenta os reflexos da ausência de outros grupos raciais no campo universitário:

Um professor negro contou-me, recentemente, um episódio constrangedor: deu a primeira aula do semestre de uma disciplina do curso de Medicina em uma universidade particular carioca a uma turma de 68 alunos com apenas 2 negros. Quando entrou na sala, dois dias depois, para começar a segunda aula, alguns dos alunos brancos surpreenderam-se e disseram-lhe: "O que você faz 
aqui?" "Vim dar aula, obviamente", respondeu. "Ah, mas nós pensamos que aquela aula era um trote!" Um professor negro em um curso de Medicina só pode ser um trote? Como conseguimos construir, no Brasil, um espaço acadêmico tão poderoso, numeroso e tão excludente? Quais são os mecanismos que acionamos para mantê-lo tão segregado ao longo de quase um século, apesar de tê-lo ampliado constantemente, década após década? Em suma, por que os negros não foram incluídos apesar da expansão vertiginosa experimentada pelas instituições superiores de ensino e pesquisa, nas últimas cinco décadas? Mais grave: por que nós, cientistas sociais brancos, nunca falamos desse ambiente de confinamento racial em que vivemos? (CARVALHO, 2006, p.36).

Por esse caminhar, a ampliação da acessibilidade dos grupos, até então ausentes nos meios acadêmicos, tem um caráter de democratização do sistema de acesso à educação, com compartilhamento de culturas. Não se pode conceber uma sociedade multirracial, pluralista e rica em diversidades, como é a sociedade brasileira, com seu rico capital humano segregado .

Esse tipo de segregação em nada se acrescenta de valor na identidade nacional. À vista disso, Carvalho (2006) expõem que a universidade tem que ser o lugar do diálogo, porque da troca de conhecimento o processo intercultural em que o outro não seja padronizado com o objetivo de manutenção de um projeto de poder. Com as cotas, o perfil do universitário sofre transformação não apenas no campo socioeconômico, vai-se construindo uma nova identidade, composta por negros e negras, antes ausentes do lugar acadêmico.

Ghiraldelli (2003) salienta que mais do que resgate social ou pagamento histórico, a abertura de acesso dos espaços universitários aos negros, proporciona uma quebra dos paradigmas de sociabilização das elites dominantes brancas restritas aos seus pares, criando o caldeirão cultural. Segundo o autor, as cotas contribuem na formação de uma sociedade sadia ao proporcionar aos brancos a oportunidade de eclodir seus padrões, no convívio com as diversidades:

As cotas, então, são uma forma de fazer com que um lugar tido como de socialização dos jovens seja ocupado por um grupo que não está presente nele. Essa não presença do negro na universidade pública amplia o preconceito. Afinal, elimina-se preconceito com convivência. Uma vez o negro e o índio na universidade (se eles vão se formar, é outro problema, que cabe a cada universidade), a integração da juventude poderá ocorrer e, assim, o preconceito certamente diminuirá. [...] O preconceito é alimentado à medida que o branco não encontra um negro ou um índio como médico ou como estudante de medicina na universidade 
pública. A cota serve para colocá-lo lá, não para resolver o problema educacional dos negros ou a vida de um determinado negro que pegou uma vaga de cota, mas para resolver o problema do branco que, não convivendo com o negro nos lugares que ele, branco, valoriza, alimenta o preconceito que diz "negro não entra aqui, aqui não é lugar de negro, negro é para outro tipo de serviço". Esse preconceito existe e é mensurável. Os que o negam são desinformados ou mal-intencionados. (GHIRALDELLI JR., 2003, n. p.).

É preciso considerar que o acesso à educação não é um altruísmo da elite política. Trata-se do direito de inclusão inerente a natureza da democracia e as ações afirmativas é uma resposta ao racismo.Com esta assertiva, Carvalho (2003) leciona que discutir cotas é discutir a função social das escolas públicas e sua missão de ser o espaço de diálogo.

De fato, as universidades devem, por obrigatoriedade, assumir múnus da inclusão, como um lugar da diversidade, onde a todos cabem o protagonismo de seus destinos sob pena de se desperdiçar os talentos (FERNANDES, 2017, p. 155). Diga-se de imediato, que esse é o maior prejuízo acarretado pela segregação racial que dissipa da identidade brasileira, um rico continente humano multicultural.

A Carta Política de 1988 superou o conceito de democracia majoritária ao incluir a proteção das minorias dentro de uma concepção de cidadania como um universo de todos, sem distinção de raça, gênero ou crença. Tem-se o direito de igualdade como a junção do direito de acesso a oportunidades equivalentes e também, o direito à diversidade.

Destarte, a falta de representatividade das comunidades negras no ensino superior dos quadros discentes e docentes é um obstáculo para que as universidades cumpram seu múnus de condutor de inclusão racial. As ações afirmativas proporcionam uma nova silhueta à comunidade acadêmica.

Destaca-se que recentes notícias das mídias informaram os dados do Instituto Brasileiro de Geografia e Estatística de 2018 (UOL, 2019) a registrar, pela primeira vez na história do Brasil, negros e os pardos como maioria nos cursos de ensino público superior. Importante que isso aconteça e que se mantenha as cotas raciais pelo tempo necessário a causar transformações porque a diversidade, no campo educacional, torna-se via condutora das novas culturas.

Ao romper com um perfil dominante branco, a universidade deixa de ser a reprodutora da segregação racial, tornando-se a condutora da integração dos 
povos. Assim, as universidades cumprem seu papel na construção da democracia e valorização da identidade nacional pluralista.

A ampliação dos debates, além de refletir na construção da plena identidade nacional, apresenta-se como prosperidade ao revelar os cenários de multiculturalismo brasileiro. Tem-se ainda que os reflexos da escolarização impacta no acesso ao mercado de trabalho e reduz as barreiras que impedem a mobilidade social da população negra.

Lopéz (2013) escreve que as ações afirmativas abrem-se ao diálogo intercultural em cuja mobilização política de sujeitos acrescenta com seu lugares de fala, a riqueza da multiculturalidade.

Para a autora, essa ideia de interculturalidade é o produto do condicionamento das convivências, no qual as instituições são compelidas a lidar com as diferenças. Por força das cotas, inaugura-se para a construção de um projeto de nação plural democratizada.

Silva (2020) assevera que o Estatuto Racial recrimina o Estado apartidário frente as desigualdades sociorraciais e enfatiza que "[...] a igualdade a ser garantida à população negra, é a equivalência de espaços dentro das comunidades [...]" (SILVA, 2020, n.p.).

Não se pode olvidar que as cotas enfrentam a ausência dos corpos negros nos campos universitários. A integração de falares e saberes a um lugar comum, por si só, não tem o atributo de romper com o racismo, mas possibilita novos caminhos, novas oportunidades e novos conceitos.

\section{Considerações finais}

Democracia e igualdade têm significativo impacto na agenda política de sistema democrático voltado à ampliação das oportunidades a todos. Com isso, permite-se que as minorias possam reivindicar uma redistribuição de renda mais justa, por meio de políticas públicas que mitigue os problemas das desigualdades econômicas.

A atribuição constitucional do Estado Brasileiro é atenuar as disparidades socioeconômicas e educacionais por meio de fomento com caráter vinculativo. Logo, as inovações normativas se submetem aos ditames do Regime Democrático 
com seu sustentáculo nos princípios da igualdade, dignidade da pessoa, equidade e não retrocesso.

As cotas raciais são necessárias para a consolidação de uma ordem social competitiva correspondente a um sistema democrático. Além do mais, como política distributiva, as ações afirmativas quebram a naturalização da paisagem do negro como pobre inculto, revertendo-se estereótipos por meio da integração de novos perfis de universitários. A proteção das minorias é o fator que legitima o uso de políticas de inclusão positiva na redução das desigualdades.

Diante dos resultados positivos das ações afirmativas de cotas para negros nas universidades públicas com a redução das desigualdades provenientes de séculos de segregamento da população negra, desde o Brasil Colonial, o esfriamento dessas políticas públicas, corrompe o caráter democrático do Estado de Direito. Reclama-se, pois, a atuação enérgica das instituições governamentais e sociedades representativas dos interesses das minorias.

Não se pode perpetuar as ações afirmativas, dado que seu caráter é temporário. Mas por segurança jurídica, sua efetivação exige avaliações periódicas com as constatações de que as oportunidades constituíram-se tanto, e a tal ponto, que o determinante nas conquistas do mercado de trabalho e acesso ao ensino, não seja mais uma questão racial.

A promoção do bem de todos sem discriminação é dever do Estado e vincula seus agentes políticos, na obrigatoriedade de manusear as ferramentas jurídicas para obtenção da redução das desigualdades que gerou um quadro perverso de disparidades socioeconômicas, com reflexo na marginalização dos corpos negros. O racismo garante os privilégios de uma elite branca sob o manto de democracia racial, mas a Constituição é o escudo da garantia de acesso das minorias ao sistema educacional e à participação política.

Assim, o Princípio de não Retrocesso germina da necessidade de uma segurança jurídica que garanta a proteção do cidadão contra interesses reacionários. Resguarda-se, com inclusão positiva, políticas que avançaram na construção do lugar de diálogo e de participação popular.

Os espaços abertos dentro das universidades é uma abertura para a construção de uma nova consciência social no qual todos ganham com a construção de uma sociedade inclusiva, solidária e humana. A expectativa é que a convivência 
com as diversidades impulsione a expansão de uma democracia verdadeira, aberta para as riquezas culturais das múltiplas etnicidades.

Artigo recebido em 22 de outubro de 2020. Artigo aprovado para publicação em 09 de janeiro de 2021.

\section{Referências}

ALMEIDA, Silvio. O que Racismo Estrutural - compactado. Belo Horizonte: Letramento, 2018.

AMARO, Sarita. Racismo, igualdade racial e políticas de ações afirmativas no Brasil. Porto Alegre: Edipucrs. 2015.

ANDREWS, G. R. Negros e brancos em São Paulo (1888-1988). Bauru: Edusc, 1998.

BARBOSA, Rui. A Oração dos Moços. 1920. Disponível em: https://www.literaturabrasileira.ufsc. br/documentos/?action=download\&id=38508. Acesso em: 19 jun. 2020.

BRASIL. Constituição da República Federativa do Brasil (1988). Disponível em: http://www.planalto.gov.br/ccivil_03/constituicao/constituicao.htm. Acesso em: 16 mar. 2020.

BRASIL. Lei n. ${ }^{\circ}$ 9.100, de 29 de setembro de 1995. Disponível em: http://legislacao.planalto.gov.br/legisla/legislacao.nsf/Viw_Identificacao/lei\%209.10 0-1995?OpenDocument. Acesso em: 16 mar. 2020.

BRASIL. Estatuto da Igualdade Racial. Dispositivos Constitucionais Pertinentes Lei no 12.288, de 20 de julho de 2010. Disponível em:

https://www2.senado.leg.br/bdsf/bitstream/handle/id/496308/000898128.pdf?seque nce=1. Acesso em: 1 set. 2020.

BRASIL. Lei $n^{\circ}$ 12.711, de 29 de agosto de 2012. Dispõe sobre o ingresso nas universidades federais e nas instituições federais de ensino técnico de nível médio e dá outras providências. Disponível em: http://www.planalto.gov.br/ccivil_03/_ato2011-2014/2012/lei//12711.htm. Acesso em: 30 ago. 2018.

BRASIL. Lei $n^{\circ} 12.990$, de 9 de junho de 2014. Dispõe sobre reserva aos negros $20 \%$ (vinte por cento) das vagas oferecidas nos concursos públicos para provimento de cargos efetivos e empregos públicos no âmbito da administração pública federal, das autarquias, das fundações públicas, das empresas públicas e das sociedades 
de economia mista controladas pela União. Disponível em: https://presrepublica.jusbrasil.com.br/legislacao/123011825/lei-12990-14. Acesso em: 21 set 2020.

BRASIL. Lei $n^{\circ}$ 7.423, de 03 de julho de 1968. Dispõe sobre o preenchimento de vagas nos estabelecimentos de ensino agrícola. Disponível em: http://www.planalto.gov.br/ccivil_03/leis/1950-1969/L5465.htm. Acesso em: 15 ago. 2020.

BRASIL. Lei $n^{\circ}$ 8.213, de 24 de julho de 1991 -Institui a Lei Brasileira de Inclusão da Pessoa com Deficiência (Estatuto da Pessoa com Deficiência). Disponível em: http://www.planalto.gov.br/ccivil_03/_ato2015-2018/2015/lei/l13146.htm. Acesso em: 16 mar. 2020.

BRASIL. Supremo Tribunal Federal. ADI n. ${ }^{\circ} 41$, 2017. Requerente: Conselho Federal da Ordem dos Advogados do Brasil - CFOAB; Relator: Luís Roberto Barroso; Brasília/DF. Disponível em: https://www.google.com/url?sa=t\&source=web\&rct=j\&url=http://redir.stf.jus.br/pagin adorpub/paginador.jsp\%3FdocTP\%3DTP\%26docID\%3D13375729\&ved=2ahUKE wiy09SYw_HIAhWIILkGHWhHAWIQFjABegQIBRAB\&usg=AOvVaw35cEjHbcaLEn -fQ0Z5cU5q\&cshid=1574003306518. Acesso em: 17 jun. 2020.

BRASIL. Supremo Tribunal Federal. ADPF $n .^{\circ}$ 186/DF, 2012, Requerente: DEMOCRATAS - DEM; Relator: MIN. Ricardo Lewandowski; Brasília/DF, 26/04/2012. Disponível em: https://stf.jusbrasil.com.br/jurisprudencia/25342750/arguicao-de-descumprimentode-preceito-fundamental-adpf-186-df-stf/inteiro-teor-159438543?ref=juris-tabs. Acesso em: 17 set. 2020.

CARDOSO, Adriana Regina Dias; CARDOSO, Luiz Eduardo Dias; VAH, Queila de Araújo Duarte. Segurança jurídica, proteção da confiança e proibição de retrocesso: tríade fundamental à garantia e manutenção dos direitos sociais. Revista da EMESC, v. 22, n. 28, p. 303-311, 2015. Disponível em: https://www.google.com/url?sa=t\&source=web\&rct=j\&url=https://revista.esmesc.or g.br/re/article/download/131/110\&ved=2ahUKEwiaw6qVmcjsAhUpK7kGHS93Av0 QFjAAegQIDxAB\&usg=AOvVaw1OI24H4Ce7hLeDsE5_Stsq. Acesso: 17 out. 2020.

CARVALHO, José Murilo de. Cidadania no Brasil: O longo caminho. 3. ed. Rio de Janeiro: Civilização Brasileira, 2002, 226 p.

CARVALHO, J. J. As ações afirmativas como resposta ao racismo acadêmico e seu impacto nas ciências sociais brasileiras. Brasília: UnB, Departamento de Antropologia, 2003. (Série Antropologia, 358). Disponível em: https://www.google.com/url?sa=t\&source=web\&rct=j\&url=http://flacso.org.br/\%3Fp ublication\%3Das-acoes-afirmativas-como-resposta-ao-racismo-academico-e-seuimpacto-nas-ciencias-sociaisbrasileiras\&ved=2ahUKEwjznJSA1J_oAhX1HrkGHd_BRkQFjAAegQIARAB\&usg =AOvVaw1 tbyMIISLmMeZ-CsdXCh23. Acesso em: 16 mar. 2020. 
CARVALHO, J. O confinamento racial do mundo acadêmico brasileiro. Revista USP, $\quad$ n. 68, p. 88-103, 1 fev. 2006. Disponível em: http://www.revistas.usp.br/revusp/article/view/13485. Acesso em: 16 fev. 2020.

CRUZ, M. C. V. e. Cor, etnicidade e formação de classe no porto do Rio de Janeio. Revista USP, São Paulo, n. ${ }^{\circ}$ 68, dez-fev. 2005.

DANTAS, Carolina Vianna. Manoel da Motta Monteiro Lopes, um deputado negro na I República. 2008. Programa Nacional de Apoio à Pesquisa - FBN/MinC. Disponível em https://primeirosnegros.com/2020/10/monteiro-lopes-o-primeirodeputado-federal-negro-do-brasil/. Acesso em 21 dez. 2020.

DIAS, Everaldo Medeiros. Cotas para negros em universidades: Função social do Estado contemporâneo e o princípio da proporcionalidade. UNIVAS/MG: Paco Editorial Edição em Versão Digital, 2017, Ebook.

DODGE, Raquel. Democracia é governo da maioria com respeito à minoria. 2019. Correio do Estado. Disponível em: https://www.correiodoestado.com.br/noticias/democracia-e-governo-da-maioriacom-respeito-a-minoria-diz-raquel/339689/. Acesso em: 24 mai. 2020.

DOTTA, Alexandre Godoy; MARQUES, Camila Salgueiro da Purificação. Programas sociais, a exclusão social e a vedação ao retrocesso: direitos sociais no Brasil em crise. Revista do Direito. Santa Cruz do Sul, v. 3, n. 53, p. 2-22, set./dez. 2017. em: https://www.google.com/url?sa=t\&source=web\&rct=j\&url=https://online.unisc.br/se er/index.php/direito/article/download/9624/6972\&ved=2ahUKEwjN18j9gKDoAhUgJ rkGHSBbAKEQFjAEegQIBxAB\&usg=AOvVaw1pnoRaS9kg9w3dXABLNERZ\&cshi $d=1584400345278$. Acesso em: 16 mar 2020.

FERNANDES, Florestan. A Integração do Negro na Sociedade de Classes: (o legado da raça branca), Volume 1, 5. ed. São Paulo: Globo, 2008a.

FERNANDES, Florestan. A integração do negro na sociedade de classes (No limiar de uma nova era): Volume 2. São Paulo: Globo, 2008b.

FERNANDES, Florestan. O Negro no mundo dos brancos. São Paulo: Global, Edição Digital, 2013.

FERNANDES, Florestan. Significado do Protesto Negro. São Paulo: Expressão Popular co-edição Editora da Fundação Perseu Abramo. 2017.

GHIRALDELLI JR., Paulo. Filosofia Política para Educadores: democracia e direito das minorias. São Paulo: Manole, Edição Digital, 2013.

GOMES, Nilma Lino O Movimento Negro educador : saberes construídos nas lutas por emancipação. Petrópolis, RJ : Vozes, 2019.

LENZA, Pedro. Direito constitucional esquematizado. 23. ed. - São Paulo : Saraiva Educação, 2019. 
LOBO, Bárbara Natália Lages. O Direito à Igualdade da Constituição Brasileira: Comentários ao Estatuto da Igualdade Racial e a constitucionalidade das ações afirmativas na Educação. Belo Horizonte: Fórum, 2013. 260 p.

LOPÉZ. Laura Cecilia. PARTE II - Dinâmicas As ações afirmativas e a possibilidade de diálogo intercultural no Brasil. In. JARDIM, Denise Fagundes. LOPÉZ. Laura Cecilia. Políticas da diversidade. Porto Alegre: Editora da UFRGS, 2013.

MELLO, Ministro Celso de. Parecer. 2017. Disponível em: http://www.stf.jus.br/portal/cms/verNoticiaDetalhe.asp?idConteudo=350957.

Acesso em: 16 maio 2020.

MIRANDA, Shirley Aparecida de. Diversidade e ações afirmativas: combatendo as desigualdades sociais - Belo Horizonte: Autêntica Editora, UFOP, 2010.

NASCIMENTO, Abdias do. 1914-2011, O genocídio de negro brasileiro: Processo de um racismo mascarado, São Paulo: Perspectivas, 2016. 232 p.

RIO DE JANEIRO. Grupo de Estudos Multidisciplinar da Ação Gema (Org.). A implementação do Pacto pela Diversidade nas universidades públicas. 2018. Disponível em: http://gemaa.iesp.uerj.br/textos-para-discussao/td18/. Acesso em: 19 maio 2020.

SOUZA, R. S. Organização e disciplina do trabalho ferroviário no pós-abolição. Revistas Mundos do Trabalho, v. 2, n. 3, jan-jul 2010.

SILVA, Eliaidina Wagna Oliveira da. Os Desafios das Ações Afirmativas na Inclusão Racial e os seus Avanços como Políticas Públicas. Publicado em 07/2020. Disponível em: https://www.google.com.br/url?sa=t\&source=web\&rct=j\&url=https://jus.com.br/amp/ artigos/83772/1\&ved=2ahUKEwiPtsjMq7TrAhXrDbkGHczIBIcQFjAAegQIBRAB\&us $\mathrm{g}=A O v V a w 3 q z d V j h 244$ evzKfGtYpMe0\&ampcf=1. Acesso em: 25 ago. 2020.

SILVA FILHO, João Antônio da. A democracia e a democracia em Norberto Bobbio. São Paulo: Editora VERBATIM, 2016. 165 p., Ebook.

STRECK, Lenio Luiz; MORAIS, José Bolzan de. Ciência Política e Teoria do Estado. $8^{a}$ Ed. Porto Alegre: Livraria do Advogado Editora Ltda., 2014.

UOL. Pretos pardos ultrapassam brancos ensino superior público. Disponível em: https://m.vestibular.brasilescola.uol.com.br/noticias/pretos-pardos-ultrapassambrancos-no-ensino-superior-publico/346677.html. Acesso em: 24 ago. 2020. 